\title{
Travel medicine and general practice: a suitable case for audit?
}

\author{
David S G Sloan
}

Travel medicine becomes more important with the continual expansion of international travel and the increased popularity of exotic holiday destinations. In the United Kingdom general practitioners provide the bulk of travel health advice and immunisation and there is growing interest in providing these services. While their armamentarium has been expanded with attractive but expensive new vaccines, the need for health service advice has never been more vital, with the risks of HIV infection and drug resistant malaria. Advantages of a general practice based travel medicine service include maintaining continuity of care for the patient, but a disadvantage might be that the general practitioner sees too few patients to acquire enough skill in the subject. Furthermore, there may be a conflict of interest between time devoted to the "vaccination ritual" and giving health advice. Overall there seems to be a case for both audit and support by the health authorities.

Travellers abroad have high rates of illness and death. ${ }^{12}$ In the past 40 years the numbers of British people travelling beyond Europe have multiplied more than 20-fold. ${ }^{2}$ Travellers are going on "adventure holidays" to countries with more, and more unfamiliar, health hazards. ${ }^{3}$

\section{Where can travellers get health advice?}

Where may these travellers get health advice? There are some specialised private services such as British Airways clinics. Some clinics are organised through health authorities, including centres of excellence based at hospitals of tropical medicine and infectious diseases. Much of the provision, however, is from general practice. Travel brochures and the government's own booklet Health Advice for Travellers ${ }^{4}$ advise people to turn to their general practitioners, and both travellers and doctors believe that primary care is the best setting for pre-travel advice (W S J Arnold, paper presented at third international conference on tourist health, Venice, 1990). ${ }^{5}$

General practitioners seem to have responded to this demand in an entrepreneurial spirit. Between 1990 and 1992 the total number of yellow fever vaccination centres rose from 338 to 1496 , the great bulk of the increase being due to new centres based in general practice (from 181 to 1231). ${ }^{67}$ Articles by and for general practitioners appear in their journals explaining how to set up and run immunisation clinics and how best to claim and charge for such services. ${ }^{8-10}$ Some critics have questioned quality, consistency, and cost of the present provision of advice on travel medicine and how best to organise and provide it (C Bartlett, personal communication, 1992). ${ }^{1112}$

In this paper I examine the advantages and drawbacks of a general practitioner service, what information back up it has, and various issues and problems that are occurring.

\section{Advantage of a general practitioner service}

Members of the public use our accessible primary care system for most of their children's immunisation, for much health advice, and for most of their own health problems. Why should the provision of travel health advice and immunisations be any different? General practitioners know their patients' medical histories, ${ }^{5}$ will manage any reactions to travel immunisations, and will deal with illness or injury contracted abroad.

Every general practitioner is provided with an official book, Immunisation Against Infectious Disease, that contains information on all vaccines. The 1992 edition contained a new chapter on immunisation for foreign travel. ${ }^{7}$ Health Advice for Travellers contains more useful advice. ${ }^{4}$ Other official sources include the British National Formulary, ${ }^{1}$ the ABPI Data Sheet Compendium, and the Prescribers' Fournal.

Several magazines for general practitioners have news and feature articles on travel health and immunisation, and two feature monthly charts of recommended immunisations and malaria prophylaxis. Further information is available from pharmaceutical companies and books (directed at medical or lay readers) ${ }^{13-16}$ and specialised journals such as Travel Medicine International. Travax is a constantly updated database in travel medicine and immunisation requirements organised by the Communicable Disease (Scotland) Unit. General practitioners with the general practice administration system for Scotland (GPASS) can link into this, and those with other systems can do so with extra effort. ${ }^{5}$

\section{Health authority obligations}

Each health authority must have a designated immunisation coordinator and a consultant in communicable disease control-often the same personwho may be consulted about travel immunisations. These people produce newsletters and usually have access to up to date information through regular publications from the Communicable Disease Surveillance Centre and the World Health Organisation. General practitioners may also get advice from local infectious disease physicians or the medical staff of health authority yellow fever vaccination centres. Clinics run by national and regional departments of tropical disease and infectious disease accept direct inquiries or referrals of general practitioners' patients. The Communicable Disease Surveillance Centre's travel unit and the Communicable Disease (Scotland) Unit answer inquiries on travel immunisations from general practitioners.

\section{Problems with a general practitioner service}

A general practitioner may not see enough patients planning travel outside Europe to acquire familiarity and skill in the subject. One study found that most general practitioners asked about cholera immunisation would have recommended it inappropriately, ${ }^{17}$ and another showed that advice from general practitioners was inconsistent. ${ }^{18}$ Both found that appropriate advice ${ }^{1718}$ was not always given.

Setting up a yellow fever vaccination centre does not guarantee the quality of the service. The departments of health require only that such a centre should be under the control of a registered medical practitioner and that a suitable secure refrigerator is provided $(\mathrm{O} \mathrm{A}$ 
Thores, personal communication, 1993). There is a proviso for inspections, but these are rare, and no criteria have been laid down for the quality of the service delivered.

The main cost to the NHS from measures for preventing travel associated illness are the costs of vaccines and their delivery. This bill is likely to rise dramatically owing to the greater interest among general practitioners in providing travel clinics and the recent licensing of expensive vaccines against hepatitis $A$ and typhoid that are preferred by travellers to the old ones.

A course of hepatitis A vaccine $(£ 40.80)$ can now provide long term protection. ${ }^{719}$ Previously only six months' protection could be guaranteed from a painful injection of human normal immunoglobulin costing $£ 6.50 .^{719}$ Guidelines for using the new vaccine imply that it might be given to over five million British travellers a year. ${ }^{20} 21$

Two new typhoid vaccines were introduced in $1992^{22}$ which have fewer side effects. Only one dose of the vi antigen vaccine is needed for three years' protection. The other live (Styph Ty21) vaccine may be self administered orally. They are respectively five and 12 times more expensive per course than the old vaccine. ${ }^{19}$ The government booklet Health Advice for Travellers recommends immunisation for visitors to 151 out of 204 countries outside the European Community. ${ }^{4}$

Giving typhoid vaccine and human normal immunoglobulin attracts a payment ${ }^{23}$ and, though there has been debate ${ }^{24} 25$ over the new vaccine, it seems that payment will also apply to the hepatitis $B$ vaccine and the vi typhoid vaccine in England. Even without such payment the BMA recommends that a fee of $£ 17.50$ can still be charged (personal communication, 1992). Experience shows that a fee for service payment encourages doctors to maximise such services. ${ }^{26}$ So even when there is an option (see below) probably immunisation will be favoured.

\section{Appropriateness}

Travel company brochures, government publications, and general practitioner periodicals all seem fixated on immunisation. ${ }^{117}$ Travel medicine should be founded on risk assessment, ${ }^{11}$ but this is unlikely to be vigorously applied where the "vaccination ritual" is the norm. ${ }^{22}$ For example, the risks of hepatitis $\mathrm{A}$ in Turkey are small during a modern hotel holiday

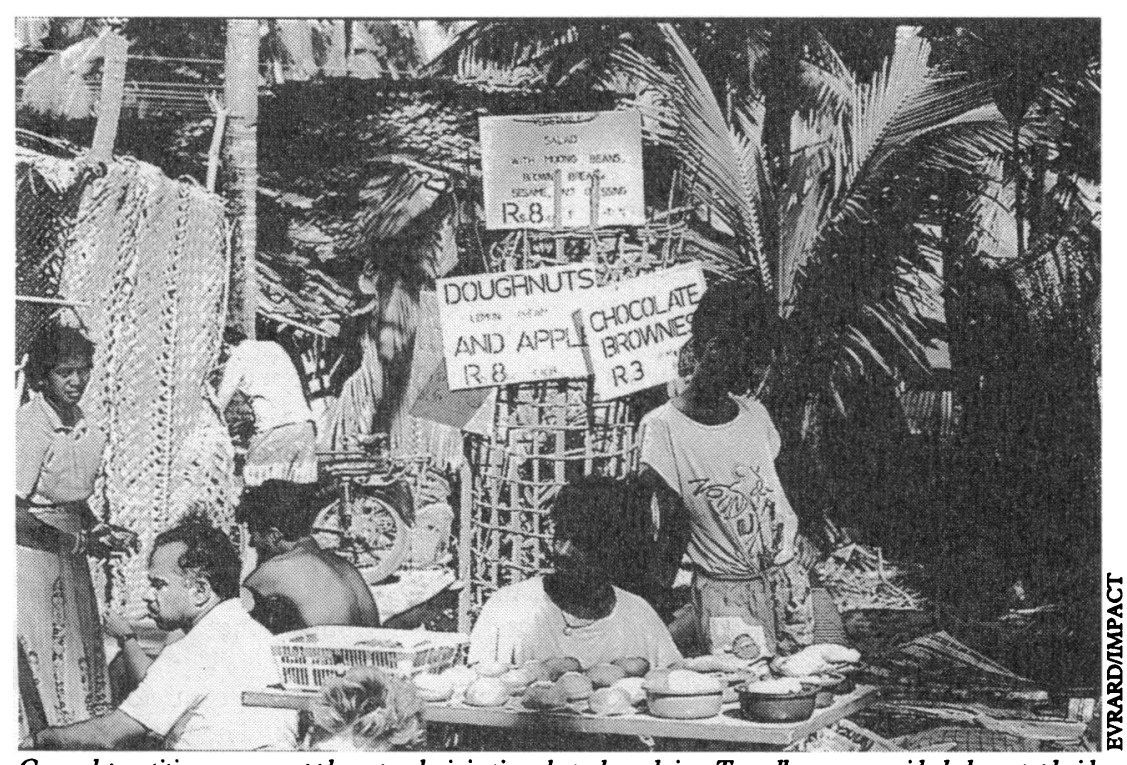

General practitioners can supply not only injections but also advice. Travellers can avoid cholera, typhoid, hepatitis $A$-and diarrhoea-by sterilising water, thoroughly cooking meat and eating it while hot, cooking vegetables, and peeling fruit compared with a backpacking trip. ${ }^{11}$ Typhoid is rare, yet millions of travellers are immunised against it annually. ${ }^{22}$ Cholera immunisation is not advised by the World Health Organisation and is rarely justified, yet one study ${ }^{17}$ estimated that inappropriate immunisations cost the NHS $£ 650000$ in 1987. Many travellers are already immune to hepatitis $A$ and do not need human normal immunoglobulin or the new vaccine. Antibody checks are recommended for those over $50^{720}$ and among younger travellers in Scotland. ${ }^{27} 28$ This recommendation seems likely increasingly to be ignored-for it demands extra time and effort, in contrast with the attraction of immediate immunisation to general practitioners and their patients.

\section{Health advice}

The commonest cause of illness abroad is travellers' diarrhoea. This cannot be prevented by immunisation, ${ }^{113}$ but it can be avoided by following simple advice when eating and drinking. ${ }^{713}$ Cholera, typhoid, and hepatitis $\mathrm{A}$ are preventable by immunisation, but they can be avoided by following the same advice. The vaccines against typhoid and cholera do not offer complete protection, ${ }^{7722}$ can be obviated by large infective doses, ${ }^{22}$ and their acquisition may give travellers a false sense of security. ${ }^{17}$

It is sensible to avoid mosquito bites. This also reduces the risk of illnesses such as dengue fever (against which there is no effective prophylaxis) and malaria. Such advice is becoming increasingly important as chloroquine resistant strains of malaria become more prevalent. ${ }^{1229-31}$ Travellers' activities may put them at risk of sexually transmitted diseases and HIV infection. ${ }^{32}{ }^{33}$ Advice on avoiding risky sexual behaviour is important, but such counselling in primary care needs improving. ${ }^{34}$ Trauma is the greatest cause of excess deaths in travellers, ${ }^{1}$ and some simple advice on avoiding moped accidents in Corfu or drowning tragedies in Greece might well be beneficial.

Will this important health education be covered adequately in a consultation? Professor Abel-Smith observed that "if a fee is paid for an injection but no fee for issuing a prescription, there is an incentive in favour of injections. ${ }^{26} \mathrm{He}$ might well have added in the present climate of opinion favouring vaccination that injections would be even more favoured than giving time consuming advice. ${ }^{17}$ At least one study has confirmed this paucity of health advice. ${ }^{18}$

\section{Need for audit and support}

My analysis suggests that more attention should be given to providing appropriate and adequate health advice and immunisation for travellers. The departments of health do not attempt to audit the activities of the yellow fever vaccination centres that they authorise.

I believe that each purchasing authority should be required (through its department of public health ${ }^{11}$ ) to ensure an adequate travel medicine service. This might be a mix of existing authority clinics and general practitioner services, or just general practitioner services. Family health services authorities or their equivalent need to monitor the costs associated with "travel" vaccines. To ensure an appropriate and cost effective service some method of audit is needed, and a pilot scheme is being considered ( $R$ Mayon-White, personal communication, 1993). Adequate specialist advice in each area should be identified by the health authority and support via newsletters and relevant updates and so on provided to general practitioners.

1 Lea G. Health risks of travel. PHLS Microbiology Digest 1992;9:132-3.

2 Cossar JH, Reid D. Health hazards of international travel. World Health Stat 0 1989;42:61-9. 
3 Phillips-Howard PA, Breeze E, Larkin C, Bradley DJ. Short-term travel to malarious areas; malaria risk in British residents. Travel Medicine International 1988;6:51-60.

4 Department of Health, Central Office of Information. Health advice for travellers: anywhere in the world. London: HMSO, 1993. (Leaflet T4.)

5 Cossar JH, Reid D. Immunisation and health advice for travellers: the role of the general practitioners. Health Bull (Edinb) 1992;50:428-32.

6 Department of Health, Welsh Office, Scottish Home and Health Department. Immunisation against infectious disease. London: HMSO, 1990.

7 Department of Health, Welsh Office, Scottish Home and Health Department. Immunisation against infectious disease. London: HMSO, 1992.

8 Travel immunisation. Monthly Index of Medical Specialties 1992;19:58-9.

9 Practice and money guide, immunisation policy and fees. General Practitioner 1992 Oct 23:79-86.

10 Immunisation for travellers. New rules will reduce many GPs' incomes, but there are ways to earn more. General Practitioner 1992 Oct 30:57.

11 Porter JDH, Stanwell-Smith R, Lea G. Travelling hopefully, returning ill. BMF 1992;304:1323-4.

12 Travellers' health. Public Health News 1992;3:127-8.

13 World Health Organisation. International travel and health, 1992. Geneva: WHO, 1993.

14 Walker E, Williams G. $A B C$ of healthy travel. 3rd ed. London: BMJ Publishing Group, 1989.

15 Dawood R, ed. Travellers' health. 3rd ed. Oxford: Oxford University Press, 1992.

16 Turner AC. Travellers' health guide. 4th ed. London: Lascelles, 1991

17 Mott A, Kinnersley P. Overprescription of cholera vaccine to travellers by general practitioners. $B M \mathcal{F} 1990 ; 300: 25-6$.

18 Usherwood V, Usherwood TP. Survey of general practitioners' advice for travellers to Turkey. $f R$ Coll Gen Pract 1989;39:148-50.

19 Joint Formulary Committee 1992-1993. Immunological products and vaccines.
In: British national formulary. No 25. London: British Medical Association, Pharmaceutical Press, 1993:458-66.

20 Lea G. Advice for travellers. Communicable Disease Report 1992;2:R82-3.

21 Black ME, Begg N, Behrens RH. Hepatitis A vaccination. Lancet 1992;340: 244.

Typhoid vaccination: weighing the options. Lancet 1992;340:341-2.

23 National Health Service General Medical Services. Statement of fees and allowances payable to general medical practitioners in Scotland from 1 April allowances payable to general medical practitioners in Scotland from 1 1990. Edinburgh: Scottish Home and Health Deparment, 1992:57-8.

24 Blackburn J. Problems with payment for travel immunisation. Pulse 1992;52. 49-51.

25 Ingram M. New hepatitis A vaccine can give a boost to GPs. General Practitioner 1992 April 3:34.

26 Abel-Smith B. Value for money in health services. London: Heinemann, 1976 61-2.

27 Cossar $\mathrm{JH}$, Reid $\mathbf{D}$. Not all travellers need immunoglobulin for hepatitis $\mathbf{A}$. $B M 7$ 1987;294:1503.

28 Kudesia G, Follet EAC. Not all travellers need immunoglobulin for hepatitis A. $B M \mathcal{F} 1987 ; 295: 118$.

29 Malaria. Wkly Epidemiol Rec 1992;67:349-50.

30 Malaria. Deaths in the United Kingdom. Communicable Disease Repor 1992;2:141.

31 Brook MG, Bannister BA. The clinical features of imported malaria. Communicable Disease Report 1993;3:R28-31.

32 Barlow D, Sherrard J. Sexually transmitted diseases. PHLS Microbiology Digest 1992;9:129-31.

33 Noone A, MacDonald N, Evans B, Heptonstall J. HIV transmission, travel and Thailand. $B M \mathcal{F}^{\prime}$ 1992;305:1431.

34 Kingman S. Difficult to give out condoms. BMF 1992;305:1314.

(Accepted 7 fuly 1993)

\section{ANY QUESTIONS}

Does a woman who forgets to take the combined contraceptive pill until several hours after intercourse need postcoital contraception?

Relevant research on this topic ${ }^{1-3}$ may be summarised by three propositions:

- Seven consecutive pills are enough to make the ovaries quiescent (therefore pills 8 to 20 in a packet simply "keep them asleep")

- Seven pills can be omitted without ovulation, as indeed is regularly the case in the pill free week, though there is significant return of follicular activity in about $23 \%$ of women ${ }^{2}$

- More than seven pills missed in total risks ovulation.

The seven day rule, as promoted by the United Kingdom Family Planning Association and also now agreed by the United Kingdom manufacturers, is based on these findings and can be conveyed in a simple algorithm (figure). ${ }^{4}$ No special action is required if pill taking is delayed by less than 12 hours.

If a woman omits some tablets around the end of her preceding packet and is allowed to restart the next packet on her usual starting day there will be a risk of ovulation at the end of the lengthened pill free-that is, contraceptive free-time after what is a falsely reassuring withdrawal bleed. A useful way of explaining that situation is to say that missing pills at the end of a packet is like making the pill free break early by mistake so that it is silly to add on the regular break.

In what circumstances might emergency (postcoital) contraception be indicated? It is justified if the woman failed to take or absorb the first two tablets or any permutation of tablets out of the first seven which the prescriber considers is substantially equivalent to that, so lengthening the pill free interval to nine or more days. She should return to regular pill taking immediately and take additional precautions for the next seven days. The woman should be counselled about the implications of failure, and a follow up visit four weeks later is essential.

Even erring on the side of caution, postcoital treatment would be overcautious for omission of up to three tablets mid-packet-that is, days 7 to 14 . For failure to take the pill during days 15 to 21 , missing out the next routine seven day break would suffice.-JOHN GUILLEBAUD, professor of family planning and reproductive health, Margaret Pyke Centre, London

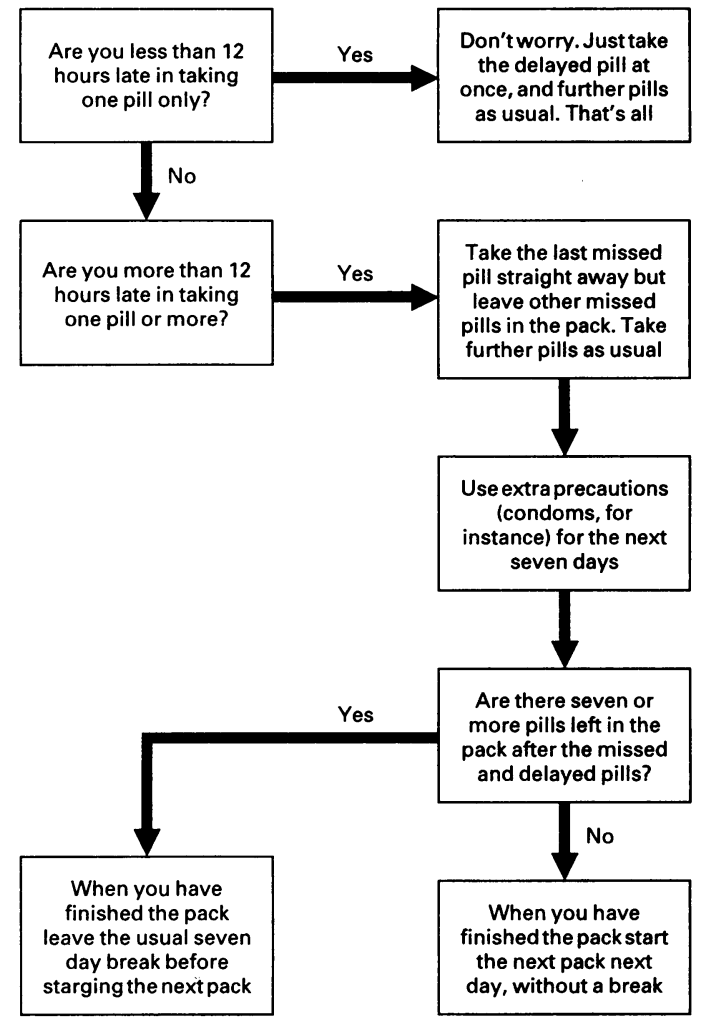

Advice for missed pills (21 day packaging)

1 Guillebaud J. The forgotten pill-and the paramount importance of the pill-free week. British foumal of Family Planning 1987;12(suppl):35-43.

2 Tayob Y, Robinson G, Adams J, Nye M, Whitelaw N, Shaw RW, et al. Ultrasound appearance of the ovaries during the pill-free interval. British foumal of Family Planning 1990;16:94-6.

3 Smith SK, Kirkman RJ, Arce BB, McNeilly AS, Loudon NB, Baird DT

The effect of deliberate omission of Trinordiol or Microgynon on the hypothalamo-pituitary-ovarian axis. Contraception 1986; 34:513-22.

4 Guillebaud J. Contraception: hormonal and barrier methods. London: Martin

Dunitz, 1992. 